\title{
Endogenous Neurotrophins Are Required for the Induction of GABAergic Long-Term Potentiation in the Neonatal Rat Hippocampus
}

\author{
Paolo Gubellini, ${ }^{1}$ Yehezkel Ben-Ari, ${ }^{2}$ and Jean-Luc Gaïarsa ${ }^{2}$ \\ ${ }^{1}$ Laboratoire "Interactions Cellulaires, Neurodégénérescence et Neuroplasticité," Centre National de la Recherche Scientifique-Unité Mixte de Recherche \\ 6186, 13402 Marseille Cedex 20, France, and 2Institut de Neurobiologie de la Méditerranée, Institut National de la Santé et de la Recherche Médicale Unité \\ 29, 13273 Marseille Cedex 09, France
}

In the developing rat hippocampus, GABAergic synapses undergo a $\mathrm{Ca}^{2+}$-dependent long-term potentiation (LTP $\left.{ }_{\mathrm{GABA}-\mathrm{A}}\right)$; this form of synaptic plasticity is induced in CA3 pyramidal neurons by delivering repetitive depolarizing pulses (DPs) to the recorded neuron, and it is expressed as a long-lasting increase in the frequency and amplitude of spontaneous $\mathrm{GABA}_{\mathrm{A}}$ receptor-mediated postsynaptic currents. In the present study, we examined the role of endogenous tropomyosin-related kinase receptor $\mathrm{B}$ (TrkB) receptor ligands and associated protein tyrosine kinases (PTKs) in the induction of $\mathrm{LTP}_{\mathrm{GABA}-\mathrm{A}}$. The application of Lavendustin A, a broad spectrum PTK inhibitor, blocked the induction of $\mathrm{LTP}_{\mathrm{GABA}-\mathrm{A}}$, whereas Lavendustin B, its inactive form, had no effect. Moreover, k-252a and k-252b, two alkaloids that inhibit the kinase activity of the Trk receptor family, also prevented the induction of LTP ${ }_{\mathrm{GABA}-\mathrm{A}}$. On hippocampal slices incubated with the soluble form of TrkB receptor IgG (TrkB-IgG), which prevents the activation of TrkB receptors by endogenous ligands, DPs failed to induce $\mathrm{LTP}_{\mathrm{GABA}-\mathrm{A}}$, whereas the incubation with TrkA-IgG or TrkC-IgG had no such effect. Altogether, these data indicate that endogenous TrkB ligands and associated PTK activity are necessary for the induction of GABAergic LTP in the developing rat hippocampus.

Key words: BDNF; development; k-252a; Lavendustin A; neurotrophins; protein tyrosine kinase; synaptic plasticity

\section{Introduction}

Long-term potentiation (LTP) is a form of activity-dependent change in synaptic efficacy that has been proposed to play a crucial role in learning and memory, pathological states of neuronal excitability, and the formation of proper synaptic connections. Over the past decades, the most extensive characterization of the cellular mechanisms involved in the induction and maintenance of LTP has been undertaken at glutamatergic synapses. However, both GABAergic and glycinergic synapses also undergo longterm plasticity in several brain regions (for review, see Gaïarsa et al., 2002). As for glutamatergic LTP, a rise in intracellular $\mathrm{Ca}^{2+}$ concentration is important in shaping the strength of inhibitory synapses. The pathway through which this $\mathrm{Ca}^{2+}$ rise is translated into long-term changes of synaptic efficacy involves the activation of protein kinases (Kano and Konnerth, 1992; Kano et al., 1996). Although a considerable body of evidence indicates that brain-derived neurotrophic factor (BDNF) and associated protein tyrosine kinases (PTKs) contribute to the induction of glu-

Received Aug. 4, 2004; revised May 10, 2005; accepted May 14, 2005.

This work was supported by the Institut National de la Santé et de la Recherche Médicale. P.G. was a recipient of a Fondation pour la Recherche Médicale grant in 2001 and a Centre National de la Recherche Scientifique contract (Chargé de Recherche Associé) in 2003.

Correspondence should be addressed to Dr. Paolo Gubellini, Interactions Cellulaires, Neurodégénérescence et Neuroplasticité, Centre National de la Recherche Scientifique 31 Chemin Joseph Aiguier, 13402 Marseille Cedex 20, France. E-mail: paolo.gubellini@Incf.cnrs-mrs.fr.

D0l:10.1523/JNEUROSCI.0824-05.2005

Copyright $\odot 2005$ Society for Neuroscience $\quad$ 0270-6474/05/255796-07\$15.00/0 tamatergic LTP (O’Dell et al., 1991; Grant et al., 1992; Huang and Hsu, 1999), little is known about their possible role in the induction and/or maintenance of synaptic plasticity at inhibitory synapses (Kotak et al., 2001).

In previous studies, we reported that GABAergic synapses in the developing rat hippocampus undergo a $\mathrm{Ca}^{2+}$-dependent LTP of $\mathrm{GABA}_{\mathrm{A}}$ receptor-mediated transmission following the application of repetitive depolarizing pulses (DPs) (Caillard et al., 1999). This GABAergic LTP is induced by a conditioning protocol relevant to physiological conditions, and it is present during a narrow postnatal time window (Gubellini et al., 2001). In the present study, we investigate the possible contribution of PTKs and endogenous tropomyosin-related kinase receptor B (TrkB) ligands in the induction and expression of this form of synaptic plasticity.

\section{Materials and Methods}

Brain slice preparation. Experiments were performed on hippocampal CA3 neurons obtained from male Wistar rats between postnatal day 4 (P4) and P8. All animal experiments have been performed in accordance with the European Communities Council Directive. Hippocampal slices, $600 \mu \mathrm{M}$ thick, were obtained as described previously (Gubellini et al., 2001) and submerged in artificial CSF (ACSF) at room temperature, with the following composition (in $\mathrm{mM}$ ): $126 \mathrm{NaCl}, 3.5 \mathrm{KCl}, 2 \mathrm{CaCl}_{2}, 1.3$ $\mathrm{MgCl}_{2}, 1.2 \mathrm{NaH}_{2} \mathrm{PO}_{4}, 25 \mathrm{NaHCO}_{3}$, and 11 glucose, $\mathrm{pH} 7.4$, gassed with $95 \% \mathrm{O}_{2}$ and $5 \% \mathrm{CO}_{2}$. Slices were then transferred to a submerged recording chamber and perfused with ACSF $(2.5-3 \mathrm{ml} / \mathrm{min})$ at $34^{\circ} \mathrm{C}$.

Whole-cell recordings. Whole-cell patch-clamp recordings were performed with an Axopatch 200B amplifier (Axon Instruments, Foster 
City, CA). Borosilicate microelectrodes (4-8 $\mathrm{M} \Omega$ ) were filled with an internal solution composed of the following (in $\mathrm{mm}$ ): $110 \mathrm{CsCl}, 30$ K-gluconate, $10 \mathrm{HEPES}, 1.1 \mathrm{EGTA}, 0.1 \mathrm{CaCl}_{2}, 4 \mathrm{MgATP}$, and $0.3 \mathrm{NaGTP}$. Our conditioning protocol consisted of $20 \mathrm{DPs}$, each lasting $500 \mathrm{~ms}$ and ranging from $-80 /-90$ to $-20 / 0 \mathrm{mV}$, delivered at $0.1 \mathrm{~Hz}$. Each DP evoked a large inward current (Fig. 1 A, inset) (Gubellini et al., 2001). These DPs trigger an increase in intracellular $\mathrm{Ca}^{2+}$ because of the opening of voltage-activated calcium channels (Caillard et al., 1999). During experiments, series resistance $\left(R_{\mathrm{s}}\right)$, capacitance, and membrane resistance $\left(R_{\mathrm{m}}\right)$ were determined on-line with Acquis 4.0 software (ACQUIS1; G. Sadoc, Bio-Logic, Orsay, France). Spontaneous GABAergic activity was monitored and recorded by pClamp software (Axon Instruments). Cells with unstable $R_{\mathrm{m}}$ or $R_{\mathrm{s}}$ were discarded from data analysis.

Data acquisition and analysis. The spontaneous $\mathrm{GABA}_{\mathrm{A}}\left(\mathrm{sGABA}_{\mathrm{A}}\right)$ receptor-mediated synaptic activity was stored on-line on a personal computer and analyzed off-line with Mini Analysis 5.6 software (Synaptosoft, Leonia, NJ) and Prism 3.03 (GraphPad, San Diego, CA). The threshold for detection was set at four times the SD of the baseline noise. The fact that no false events would be identified was confirmed by visual inspection for each experiment. To calculate the amplitude of spontaneous $\mathrm{GABA}_{\mathrm{A}}$ postsynaptic currents (PSCs), multiple overlapping events were discarded. For data presented as mean \pm SEM, statistical analysis was performed using a paired Student's $t$ test. To determine whether GABAergic LTP was induced, we compared the interevent interval cumulative distribution before and after the conditioning protocol for each cell by the Kolmogorov-Smirnov (K-S) test. The area of the DP-induced calcium inward current was calculated by integrating the current underlying the event itself. Statistics about presented data, when not shown in the Results, are reported in the figure.

Drugs. 6-Cyano-7-nitroquinoxaline-2,3-dione (CNQX), D-2-amino5-phosphovaleric acid (D-AP-5), and tetrodotoxin (TTX), were obtained from Tocris Cookson (Bristol, UK); k-252a and k-252b were obtained from Calbiochem (La Jolla, CA). All of these drugs were administered by dissolving them in the perfusing solution. Lavendustin A and Lavendustin B were obtained from Sigma (St. Louis, MO); both were incubated for $\geq 2 \mathrm{~h}$ before the recording. BDNF (Sigma) was dissolved at $20 \mu \mathrm{g} / \mathrm{ml}$ in PBS. To sequester endogenous Trk receptor ligands, hippocampal slices were incubated for 5-8 h in ACSF containing $5 \mu \mathrm{g} / \mathrm{ml}$ Trk-IgG (R \& D System, Minneapolis, MN) before recording. Trk-IgG is a soluble form of Trk receptor (Shelton et al., 1995), a chimera molecule in which the extracellular portion of the Trk receptor is fused to the constant fraction portion of the antibody. In the present study, we used TrkA-IgG to sequester NGF (average incubation time, $6 \pm 1 \mathrm{~h}$ ), TrkB-IgG to sequester BDNF and neurotrophin-4 (NT-4) (average incubation time, $6 \pm 1 \mathrm{~h}$ ), and TrkC-IgG to sequester NT-3 (average incubation time, $7 \pm 1 \mathrm{~h}$ ). Control experiments were conducted on hippocampal slices incubated for the same duration in ACSF alone.

\section{Results}

Spontaneous $\mathrm{GABA}_{\mathrm{A}}$ receptor-mediated postsynaptic currents were recorded from $\mathrm{CA} 3$ pyramidal neurons at a holding potential of $-60 /-70 \mathrm{mV}$ in the presence of $10 \mu \mathrm{M}$ CNQX and $40 \mu \mathrm{M}$ D-AP-5. The conditioning protocol used to induce the long-term changes in synaptic efficacy consisted of 20 DPs (see Materials and Methods for details) delivered at $0.1 \mathrm{~Hz}$. Each DP evoked a large inward current (Fig. 1 A, inset) (Gubellini et al., 2001). Figure 1 illustrates a single experiment in which DPs resulted in a long-lasting increase in $\mathrm{sGABA}_{\mathrm{A}}$-PSC frequency and amplitude: respectively, from $7 \pm 1 \mathrm{~Hz}$ in control to $15 \pm 2 \mathrm{~Hz} 30 \mathrm{~min}$ after the DPs (400 events for both; $p<0.01$; K-S test) (Fig. $1 B, D)$ and from $63 \pm 1$ to $79 \pm 2 \mathrm{pA}(p<0.01$; K-S test) (Fig. $1 C, E)$. On average, this DP protocol induced a long-term potentiation of $\mathrm{sGABA}_{\mathrm{A}}-\mathrm{PSCs}\left(\mathrm{LTP}_{\mathrm{GABA}-\mathrm{A}}\right)$, consisting a long-term increase $(\geq 30 \mathrm{~min})$ in both their frequency $(165 \pm 30 \%$ of pre-DPs; $n=$ 13 ; $p<0.05$; Student's $t$ test $)$ and amplitude $(138 \pm 20 \%$ of pre-DPs; $n=13 ; p<0.05$; Student's $t$ test $)$. These control data are
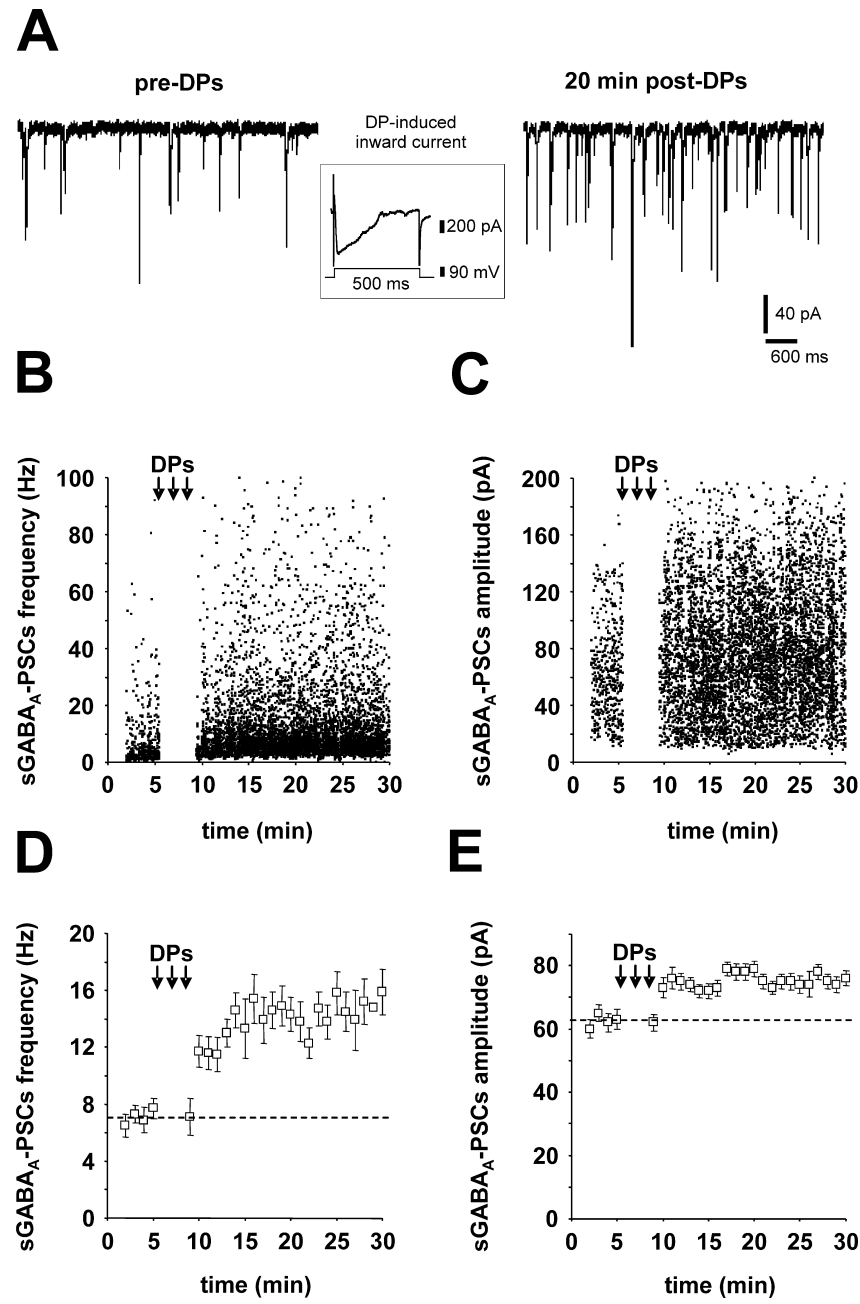

Figure 1. DPs induce $L_{T P}{ }_{G A B A-A}$, a long-lasting increase in the frequency and amplitude of $s G A B A_{A}-P S C s$. $A$, Traces from a single experiment showing $s G A B A_{A}-P S C s$ (holding potential, $-60 \mathrm{mV}$ ) recorded before (left) and $30 \mathrm{~min}$ after (right) the DP conditioning protocol (inset shows a single DP). The frequency $(\boldsymbol{B})$ and amplitude $(\boldsymbol{C})$ of $s G A B A_{A}-P S C$ s before and after the DP conditioning protocol are plotted against time (same cell as in $\boldsymbol{A}$ ). Average frequency $(\boldsymbol{D})$ and amplitude $(\boldsymbol{E})$ of $s \mathrm{GABA}_{A}-\mathrm{PSCs}$ (bin, $1 \mathrm{~min}$ ) before and after the DP conditioning protocol are plotted against time (same cell as in $\boldsymbol{A}$ ).

shown in the control column in the histograms in both Figures 2 and 3.

\section{Role of PTKs in the induction of GABAergic LTP}

To determine whether PTK activity is required for the induction of $\mathrm{LTP}_{\mathrm{GABA} A}$, we investigated the effect of Lavendustin $\mathrm{A}$, an irreversible broad-spectrum inhibitor of PTKs. Preincubation of hippocampal slices for 3-4 h in $10 \mu \mathrm{M}$ Lavendustin A had no significant effect, per se, on either basal frequency or amplitude of $\mathrm{sGABA}_{\mathrm{A}}$-PSCs: frequency in Lavendustin A was $8 \pm 2 \mathrm{~Hz}(n=7)$, versus $11 \pm 2 \mathrm{~Hz}(n=13)$ before its application $(p>0.05$; Student's $t$ test); amplitude in Lavendustin A was $61 \pm 9 \mathrm{pA}(n=$ $7)$, versus $53 \pm 6 \mathrm{pA}(n=13)$ before its application $(p>0.05$; Student's $t$ test). Similarly, currents induced by the DPs were not significantly affected by Lavendustin A: $235 \pm 77 \mathrm{nA} \cdot \mathrm{ms}$ in control condition versus $212 \pm 24 \mathrm{nA} \cdot \mathrm{ms}$ in Lavendustin $\mathrm{A}(p>$ 0.05 ; Student's $t$ test). However, in these conditions (preincubation in $10 \mu \mathrm{M}$ Lavendustin A for 3-4 h), DPs failed to induce any significant change in both frequency and amplitude of $\mathrm{sGABA}_{\mathrm{A}}{ }^{-}$ PSCs (Fig. 2) (i.e., LTP $\mathrm{GABA}-\mathrm{A}_{\text {was }}$ whibited). On average, in the 


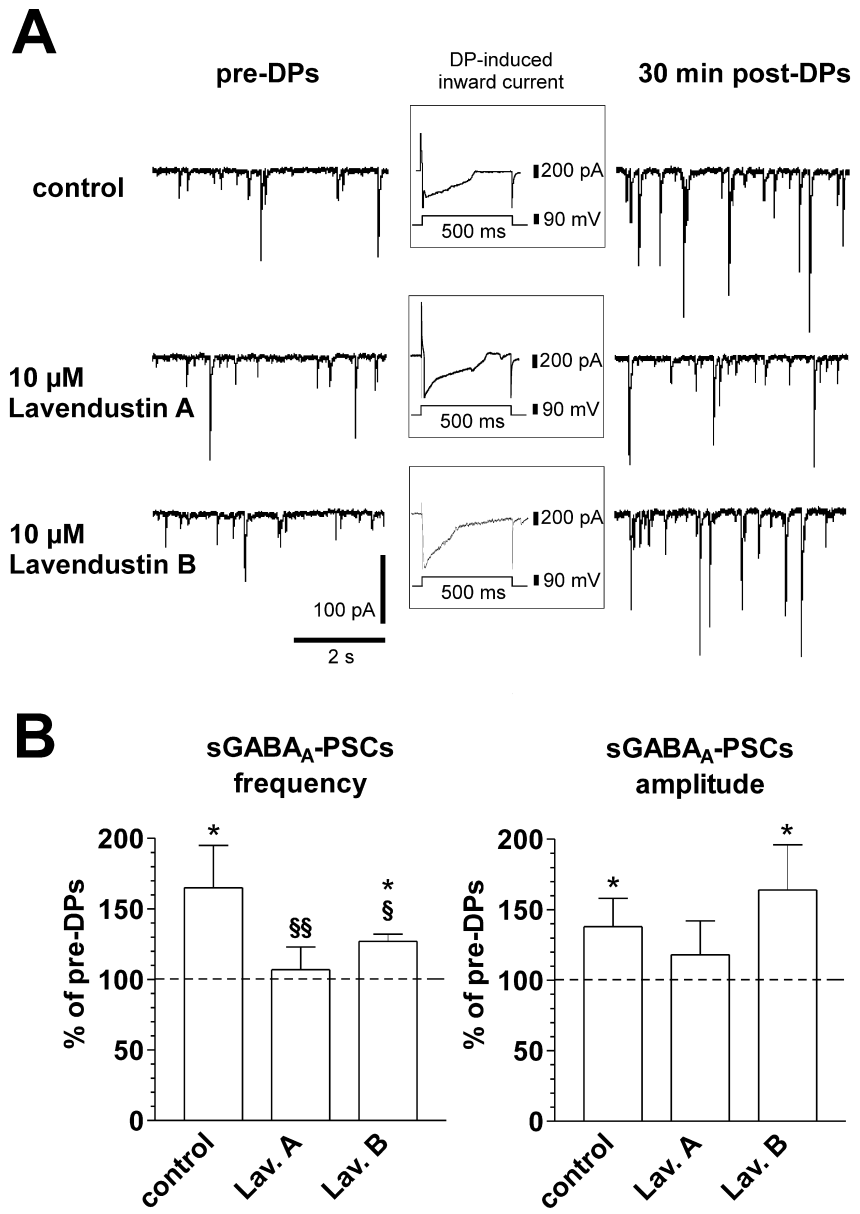

Figure 2. Role of PTKs in the induction of $\mathrm{LTP}_{\mathrm{GABA}-\mathrm{A}} \cdot \boldsymbol{A}$, Traces from a single experiment showing $S G A B A_{A}-P S C s$ before (left) and 30 min after (right) DPs. In the presence of Lavendustin $A$, a broad-spectrum inhibitor of PTKs, DPs are unable to induce LTP $_{\text {GABA-A }}$ (middle traces). Conversely, Lavendustin $B$, the inactive form, is not able to block LTP ${ }_{G A B A-A}$ (bottom traces). All cells were clamped at $-65 \mathrm{mV}$. Insets show a single DP in each condition. $B$, The histograms show the changes of frequency (left) and amplitude (right) of $S G A B A_{A}-P S C s 30$ min after the DPs. Although Lavendustin A (Lav. A) $(n=7)$ prevents significant changes of both of these parameters, its inactive form, Lavendustin B (Lav. B) $(n=6)$, does not block LTP induction $\left({ }^{*} p<0.05\right.$ compared with pre-DPs; ${ }^{\S} p<0.05$ and ${ }^{\$ \S} p<0.01$ compared with control; Student's $t$ test).

presence of this inhibitor, the frequency and amplitude of $\mathrm{sGABA}_{\mathrm{A}}$-PSCs after the DPs were, respectively, $107 \pm 16$ and $111 \pm 24 \%$ compared with pre-DPs $(n=7 ; p>0.05$ for both; Student's $t$ test). As a control for a possible nonspecific effect of Lavendustin A, its inactive analog, Lavendustin B, was used in a separate set of experiments. After preincubation with $10 \mu \mathrm{M} \mathrm{Lav-}$ endustin B, DPs were still able to trigger $\mathrm{LTP}_{\mathrm{GABA}-\mathrm{A}}$ (Fig. 2), thus confirming the specificity of Lavendustin A inhibitory effect. In these experiments, $s \mathrm{GABA}_{\mathrm{A}}$-PSC frequency and amplitude were, respectively, $125 \pm 5$ and $164 \pm 30 \%$ of pre-DPs $(n=6 ; p<0.05$ for both; Student's $t$ test).

\section{Role of Trk receptor-coupled PTKs in the induction of GABAergic LTP}

The PTKs fall in two broad categories, the receptor-coupled and the nonreceptor-coupled PTKs. The former are linked to neurotrophins and growth factors, whereas the latter are a component of the intracellular signaling cascade. Having established that a broad-spectrum inhibitor of PTKs prevents the induction of $\mathrm{LTP}_{\mathrm{GABA}-\mathrm{A}}$, we next investigated the effect of $\mathrm{k}-252 \mathrm{a}$, a more spe-
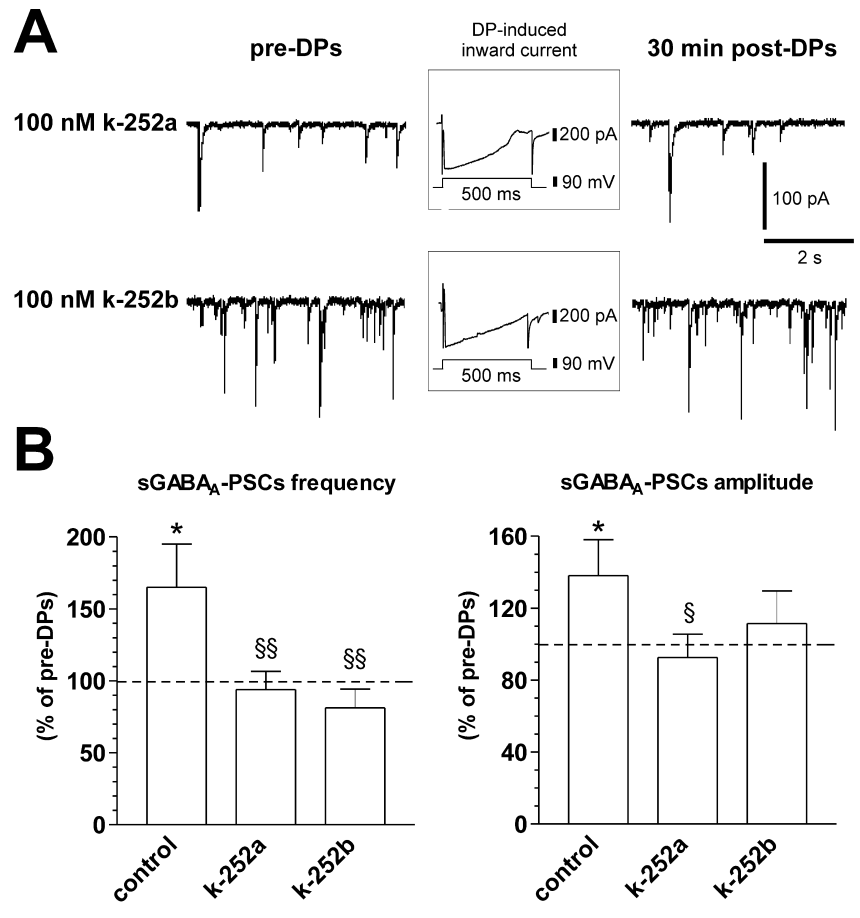

Figure 3. Role of PTKs coupled to Trk receptor family in the induction of $L T P_{G A B A-A}$. $A$, Traces from single experiments showing $\mathrm{SGABA}_{\mathrm{A}}-\mathrm{PSC}$ s before (left) and 30 min after (right) DPs, in the presence of two Trk receptor-associated PTK inhibitors, k-252a (top traces) or k-252b (bottom traces). Both of these compounds block the induction of $L_{T P} P_{G A B A-A}$. All cells were clamped at $-65 \mathrm{mV}$. Insets show a single DP in each condition. $\boldsymbol{B}$, The histograms show the changes of frequency (left) and amplitude (right) of $S \mathrm{GABA}_{A}-\mathrm{PSC} 330$ min after the DPs in control conditions and in the presence of $\mathrm{k}-252 \mathrm{a}(n=10)$ or $\mathrm{k}-252 \mathrm{~b}(n=8)$. Only in control conditions, DPs were able to induce LTP at GABAergic synapses $\left({ }^{*} p<0.05\right.$ compared with pre-DPs; ${ }^{\S} p<0.05$ and ${ }_{\S} p<0.01$ compared with control; Student's $t$ test).

cific inhibitor of PTKs coupled to Trk receptor family (Knusel and Hefti, 1992; Ross et al., 1995). k-252a (100 nM) was bath applied for 10-15 min before DPs, during DPs, and 5-10 min after DPs for a total time of 20-30 min. As shown in Figure 3, this bath application of $\mathrm{k}-252 \mathrm{a}$ prevented the induction of $\mathrm{LTP}_{\text {GABA-A }}$, whereas it had no effect on currents induced by the DPs (235 $\pm 77 \mathrm{nA} \cdot \mathrm{ms}$ in control vs $269 \pm 124 \mathrm{nA} \cdot \mathrm{ms}$ in $\mathrm{k}-252 \mathrm{a}$; $p>0.05$; Student's $t$ test). The frequency of $\mathrm{sGABA}_{\mathrm{A}}$-PSCs was $94 \pm 13 \%$ of pre-DPs, whereas amplitude was $93 \pm 13 \%$ of pre-DPs $(n=10 ; p>0.05$ for both; Student's $t$ test). Application of k-252a alone (i.e., without DPs) for 20-30 min had no significant effect per se on either frequency $(14 \pm 6 \mathrm{vs} 17 \pm 7 \mathrm{~Hz} ; n=$ $10 ; p>0.05$; Student's $t$ test) or amplitude ( $53 \pm 9$ vs $60 \pm 9 \mathrm{pA}$; $n=10 ; p>0.05$; Student's $t$ test) of $\mathrm{sGABA}_{\mathrm{A}}$-PSCs.

Similar results were obtained by using $100 \mathrm{~nm} \mathrm{k-252b}$ (Fig. 3), which is a weaker inhibitor of Trk receptor-coupled PTK (Tanaka et al., 1997). In these experiments, $\mathrm{sGABA}_{\mathrm{A}}$-PSC frequency and amplitude were $81 \pm 13$ and $111 \pm 18 \%$, respectively, of pre-DPs ( $n=8 ; p>0.05$ for both; Student's $t$ test). Therefore, these results suggest that the activation of Trk receptor-coupled PTKs is required for the induction of $\mathrm{LTP}_{\mathrm{GABA}-\mathrm{A}}$ in the developing rat hippocampus.

\section{Role of endogenous TrkB ligands in the induction of GABAergic LTP}

We next examined the possible contribution of endogenous Trk ligands. To this end, before electrophysiological recordings, hippocampal slices were incubated for $5-8 \mathrm{~h}$ in ACSF containing a neurotrophin receptor antagonist, consisting in the extracellular 
A
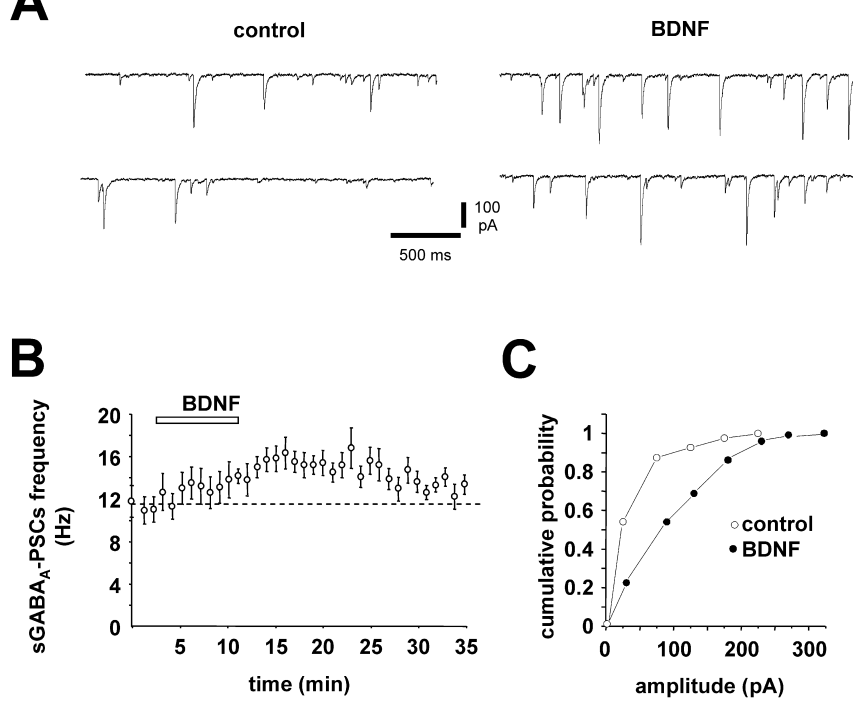

D

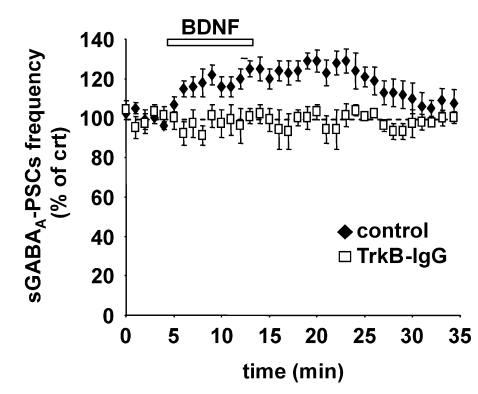

$\mathbf{E}$

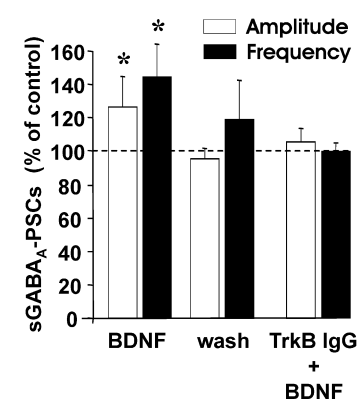

Figure 4. BDNF increases the frequency and amplitude of $s G A B A_{A}-P S C s$. $A$, Traces from a single experiment showing $s \mathrm{GABA}_{\mathrm{A}}-\mathrm{PSC}$ (holding potential, $-70 \mathrm{mV}$ ) recorded before (left) and $10 \mathrm{~min}$ after (right) BDNF onset $(20 \mathrm{ng} / \mathrm{ml})$. $\boldsymbol{B}$, Time course of the effect of BDNF on the frequency of $s G A B A_{A}-P S C S$ (bin, 1 min; same cell as in $\boldsymbol{A}$ ). $C$, Cumulative probability plot of the $\mathrm{SGABA}_{\mathrm{A}}-\mathrm{PSC}$ s amplitude (same cell as in $\boldsymbol{A}$ ) before (open circles) and $10 \mathrm{~min}$ after (filled circles) the onset of BDNF ( $p<0.05$; K-S test). D, Summary plot of the effect of BDNF on $s G_{A B A_{A}}-P S C$ frequency versus time in control $(n=9)$ and in slices preincubated with $5 \mu \mathrm{g} / \mathrm{ml} \mathrm{TrkB}-\operatorname{lgG}(n=$ 8). $\boldsymbol{E}$, The histogram shows the average change in the amplitude (open bar) and frequency (filled bar) of $s \mathrm{GABA}_{\mathrm{A}}$-PSCs induced by BDNF in control slices $(n=9)$, after 20 min of BDNF

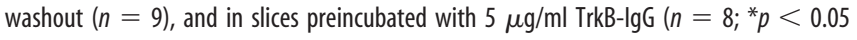
compared with before BDNF application; Student's $t$ test).

domain of each member of the Trk neurotrophin receptor fused to a human IgG Fc domain (Shelton et al., 1995): (1) TrkA-IgG (5 $\mu \mathrm{g} / \mathrm{ml}$ ) to sequester endogenous NGF, (2) TrkB-IgG ( $5 \mu \mathrm{g} / \mathrm{ml})$ to sequester endogenous BDNF and NT-4, or (3) TrkC-IgG (5 $\mu \mathrm{g}$ / $\mathrm{ml}$ ) to sequester endogenous NT-3. Control experiments consisted of hippocampal slices incubated for the same time duration in ACSF alone.

We first did a functional assay to test the penetration of TrkIgG into the slices. For control hippocampal slices, bath application of BDNF $(20 \mathrm{ng} / \mathrm{ml})$ induced a significant increase in the frequency and amplitude of $\mathrm{sGABA}_{\mathrm{A}}$-PSCs in six of nine CA3 pyramidal neurons (one cell per slice). However, in slices preincubated with TrkB-IgG, BDNF had no effect on either amplitude or frequency of $\mathrm{SGABA}_{\mathrm{A}}$-PSCs in seven of eight CA3 pyramidal neurons. These data are shown in Figure 4.

We then investigated the effect of DPs on $s G A B A_{A}$-PSCs in slices preincubated with TrkB-IgG. Although in another series of control slices DPs induced a significant increase in both fre-

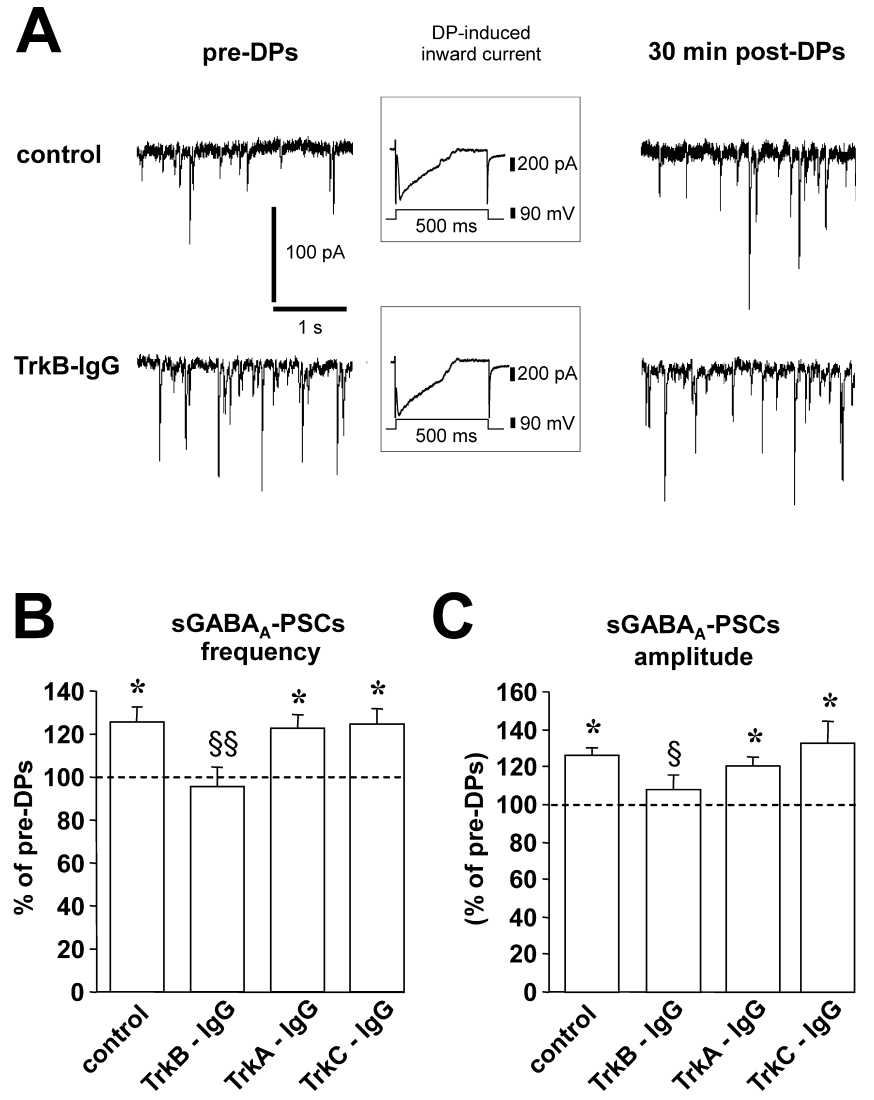

Figure 5. Role of endogenous TrkB ligands in the induction of $L_{T P} P_{G A B A-A} \cdot \boldsymbol{A}$, Traces from a single experiment show $\mathrm{SGABA}_{\mathrm{A}}$-PSCs before (left) and 30 min after (right) DPs. In control condition, a series of DPs induces a potentiation of $S G A B A_{A}-P S C$ frequency and amplitude (top traces). Conversely, in the presence of $5 \mu \mathrm{g} / \mathrm{ml} \mathrm{TrkB}-\mathrm{lgG}, D P s$ are unable to induce this form of synaptic plasticity (bottom traces). All cells were clamped at $-70 \mathrm{mV}$. Insets show a single DP in each condition. $\boldsymbol{B}$, The histogram shows the changes of frequency (left) and amplitude (right) of $s G A B A_{A}-P S C s 30$ min after the DPs in control $(n=14)$, TrkB-IgG-treated slices ( $\left.n=14\right)$, TrkA-IgG-treated slices $(n=15)$, and TrkC-IgG-treated slices $(n=15)\left({ }^{*} p<0.05\right.$ compared with pre-DPs; ${ }^{\S} p<0.05$ and ${ }^{\S \S} p<0.01$ compared with control; Student's $t$ test).

quency $(125 \pm 7 \%$ of pre-DPs; $p<0.01$; Student's $t$ test $)$ and amplitude $(126 \pm 4 \%$ of pre-DPs; $p<0.05)$ of $s G_{A B A}$-PSCs $(n=14)$ (Fig. 5), the application of TrkB-IgG prevented the induction of $\mathrm{LTP}_{\mathrm{GABA}-\mathrm{A}}$. On average, the frequency and amplitude of sGABA A PSCs were $96 \pm 9$ and $108 \pm 7 \%$, respectively, of pre-DPs $(n=14 ; p>0.05$ for both; Student's $t$ test) in the presence of this antagonist (Fig. 5). In contrast, in slices incubated with TrkA-IgG $(n=15)$ or TrkC-IgG $(n=15)$, DPs were still able to induce a significant (for both drugs, $p<0.05$ compared with pre-DPs; $p>0.05$ compared with control; Student's $t$ test) long-lasting increase in both frequency (126 $\pm 6 \%$ of preDPs and $121 \pm 4 \%$ of pre-DPs, respectively) and amplitude ( $124 \pm 7 \%$ of pre-DPs and $132 \pm 13 \%$ of pre-DPs, respectively) of $s \mathrm{GABA}_{\mathrm{A}}$-PSCs (Fig. 5).

It is important to note that incubation of the slices with TrkAIgG, TrkB-IgG, or TrkC-IgG had no significant effect per se on basal frequency and amplitude of $\mathrm{sGABA}_{\mathrm{A}}$-PSCs. Basal frequency in slices incubated in TrkA-IgG, TrkB-IgG, or TrkC-IgG was $10 \pm 2,9 \pm 2$, and $8 \pm 2 \mathrm{~Hz}$, respectively $(p>0.05$ compared with $7 \pm 2 \mathrm{~Hz}$ in control slices; Student's $t$ test), whereas amplitude was $48 \pm 4,45 \pm 5$, and $48 \pm 4 \mathrm{pA}$, respectively $(p>0.05$ compared with $56 \pm 7 \mathrm{pA}$ in control slices; Student's $t$ test). Also, currents induced by the DPs were not significantly affected by these three compounds. The average area of the DP-induced cur- 

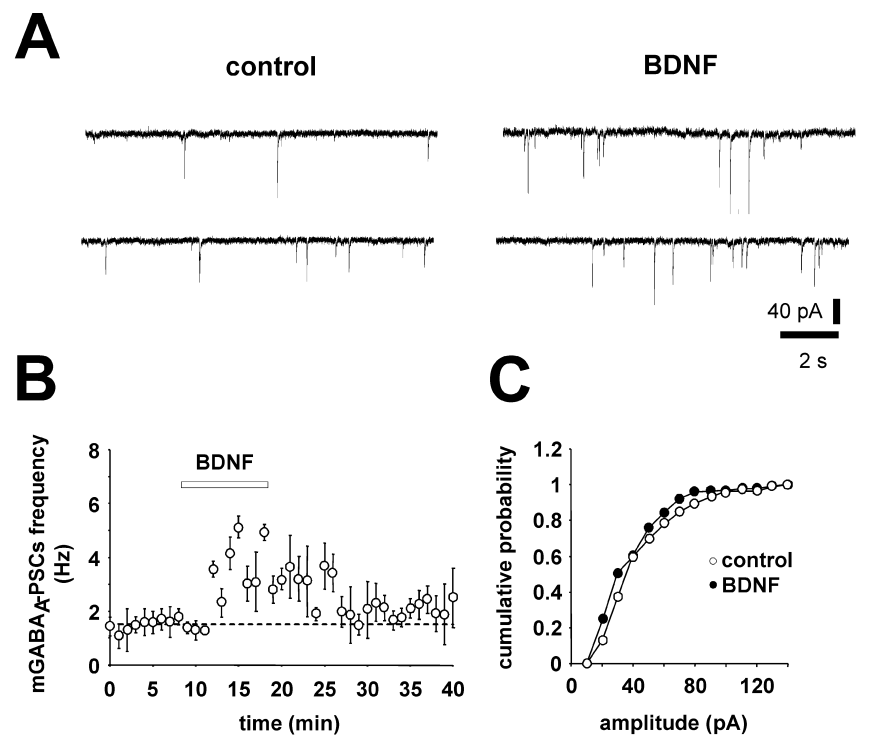

D

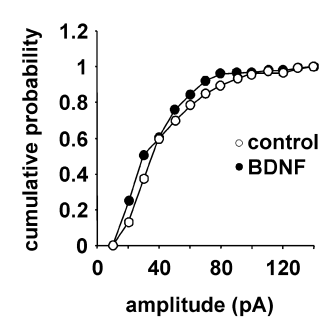

E
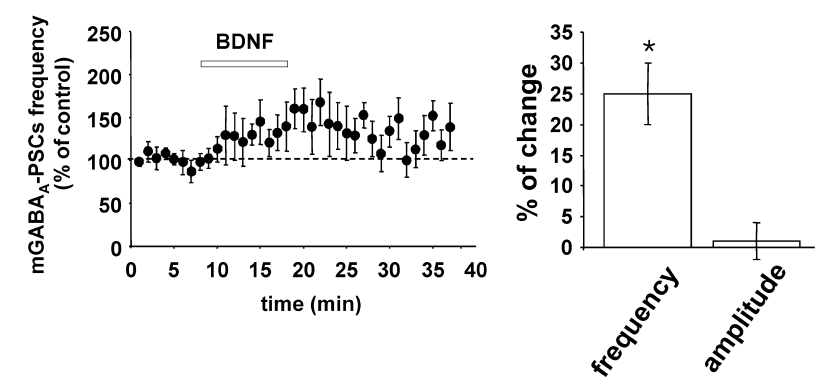

Figure 6. BDNF increases the frequency, but not the amplitude, of $m G A B A_{A}-P S C s$. $\boldsymbol{A}$, Traces from a single experiment showing $\mathrm{MGABA}_{A}-\mathrm{PSCs}$ (holding potential, $-70 \mathrm{mV}$ ) recorded before (left) and 10 min after (right) BDNF onset $(20 \mathrm{ng} / \mathrm{ml}$ ). $B$, Time course of the effect of BDNF on the frequency of $\mathrm{mGABA}_{A}-\mathrm{PSCS}$ (bin, $1 \mathrm{~min}$; same cell as in $\boldsymbol{A}$ ). $\boldsymbol{C}$, Cumulative probability plot of the $\mathrm{mGABA}_{A}-\mathrm{PSC}$ amplitude (same cell as in $\boldsymbol{A}$ ) before (open circles) and $10 \mathrm{~min}$ after (filled circles) the onset of BDNF ( $p>0.05$; K-S test). D, Summary plot of the effect of BDNF on $m_{G A B A_{A}-P S C}$ frequency versus time $(n=5)$. $\boldsymbol{E}$, Average histograms of variations in frequency and amplitude of $\mathrm{mGABA}_{\mathrm{A}}-\mathrm{PSC}$ induced by BDNF ( $n=5$; ${ }^{*} p<0.05$ compared with before applying BDNF; Student's $t$ test).

rents was $211 \pm 55 \mathrm{nA} \cdot \mathrm{ms}$ in TrkA-IgG, $182 \pm 36 \mathrm{nA} \cdot \mathrm{ms}$ in TrkB-IgG, and $158 \pm 45 \mathrm{nA} \cdot \mathrm{ms}$ in TrkC-IgG $(p>0.05$ for all, compared with $235 \pm 77 \mathrm{nA} \cdot \mathrm{ms}$ in control slices; Student's $t$ test). Therefore, it seems likely that endogenous TrkB ligands, but not of TrkA and TrkC, is required for the induction of $\mathrm{LTP}_{\mathrm{GABA}-\mathrm{A}}$ in the developing rat hippocampus.

In a previous study, we reported that DPs induced an increase in the frequency of miniature $\mathrm{GABA}_{\mathrm{A}}$-PSCs ( $\mathrm{mGABA}_{\mathrm{A}}$-PSCs) with no change in their amplitude, suggesting that $\mathrm{LTP}_{\mathrm{GABA}-\mathrm{A}}$ is expressed as an increase in the probability of GABA release (Caillard et al., 1999). To determine whether BDNF also acts presynaptically in the present study, we investigated its effect on mGABA $_{\mathrm{A}}$-PSCs isolated in the presence of $1 \mu \mathrm{M}$ TTX, $10 \mu \mathrm{M}$ CNQX, and $40 \mu \mathrm{M}$ D-AP-5. As illustrated in Figure 6, bath application of BDNF $(20 \mathrm{ng} / \mathrm{ml})$ induced a significant increase in the frequency of $\mathrm{mGABA}_{\mathrm{A}}$-PSCs $(125 \pm 5 \%$ of control; $p=0.05$; Student's $t$ test) with no change in their amplitude (101 $\pm 3 \%$ of control; $p>0.05$; Student's $t$ test; $n=5$; one cell per slice). These data also support the hypothesis that BDNF acts presynaptically in LTP $_{\text {GABA-A }}$ induction.

\section{Role of TrkB receptor-coupled PTKs in the maintenance of} GABAergic LTP

To determine whether TrkB receptor-coupled PTK activity plays a role in the maintenance of GABAergic synaptic plasticity, in another series of experiments, $\mathrm{k}$-252a was applied after the induction of $\mathrm{LTP}_{\mathrm{GABA}-\mathrm{A}}$. Figure $7 A$ illustrates one of these experiments, in which DPs induced an increase in both frequency and amplitude of $s \mathrm{GABA}_{\mathrm{A}}$-PSCs, and the application of $\mathrm{k}-252 \mathrm{a}$ had no further effect on both these parameters. Figure $7 B$ shows the pooled data obtained from eight cells in which k-252a was applied after the induction of GABAergic LTP. Thus, the stimulation of a PTK activity associated to TrkB receptors is necessary for the induction, but not for the maintenance, of LTP at GABAergic synapses.

\section{Discussion}

The development of highly organized structures in the CNS is a complex phenomenon, during which both activity-dependent and activity-independent mechanisms interact. There are several indications that long-term changes in synaptic efficacy, including long-term depression or potentiation, play a crucial role in the establishment of functional excitatory and inhibitory synapses in the developing brain (Shatz, 1990; Constantine-Paton and Cline, 1998; Gaïarsa et al., 2002). This hypothesis is based on the observation that these forms of synaptic plasticity are inducible during a restricted period of development closely matching the time window of synaptic maturation (Komatsu, 1994; Crair and Malenka, 1995; Kirkwood et al., 1995; Feldman et al., 1998; Kotak and Sanes, 2000) and that long-term modulation of synaptic strength mimics the functional maturation occurring in vivo (Isaac et al., 1997; Gubellini et al., 2001). To further strengthen this link between activity-dependent maturation and long-term plasticity, it is necessary to show that the same cellular mechanisms are involved in both phenomena. In this context, neurotrophins and related Trk receptor-coupled PTKs have been implicated in synapse development and plasticity. In cerebellar and hippocampal cultures, activity deprivation decreases the number of GABAergic synapses, an effect reversed by the application of BDNF or neurotrophin-4 (Marty et al., 2000; Seil and DrakeBaumann, 2000). Moreover, overexpression of BDNF (Aguado et al., 2003) or chronic treatment with different neurotrophins accelerates the functional maturation of GABAergic synapses (Marty et al., 1996; Vicario-Abejon et al., 1998; Schwyzer et al., 2002). BDNF and Trk receptor-coupled PTKs are also reported to play a role in the induction of LTP at glutamatergic synapses (O’Dell et al., 1991; Grant et al., 1992; Huang and Hsu, 1999).

In the present study, the observation that the induction of $\mathrm{LTP}_{\mathrm{GABA}-\mathrm{A}}$ is inhibited in the presence of Lavendustin A suggests that this form of synaptic plasticity requires the activation of PTKs. This broad-spectrum inhibitor has been reported to affect $\mathrm{GABA}_{\mathrm{A}}$ receptor function (Castel et al., 2000), and this effect might indirectly interfere with $\mathrm{LTP}_{\mathrm{GABA}-\mathrm{A}}$ induction. However, this hypothesis appeared unlikely, because the more specific inhibitors of the Trk receptor-signaling pathway (i.e., k-252a and $\mathrm{k}-252 \mathrm{~b}$ ), which had no effect on the frequency and amplitude of sGABA $_{\mathrm{A}}$-PSCs, also prevented LTP $\mathrm{GABA}_{\mathrm{A}}$. Moreover, TrkB-IgG, a scavenger of endogenous BDNF and NT-4, but not TrkA-IgG or TrkC-IgG, prevented the induction of DP-induced GABAergic LTP. Altogether, these observations demonstrate the implication of endogenous TrkB ligands, such as BDNF or NT-4, in the induction of $\mathrm{LTP}_{\mathrm{GABA}-\mathrm{A}}$ in the developing rat hippocampus.

The conditioning protocol used in the present study to induce long-term changes in GABAergic synaptic efficacy consisted of 20 

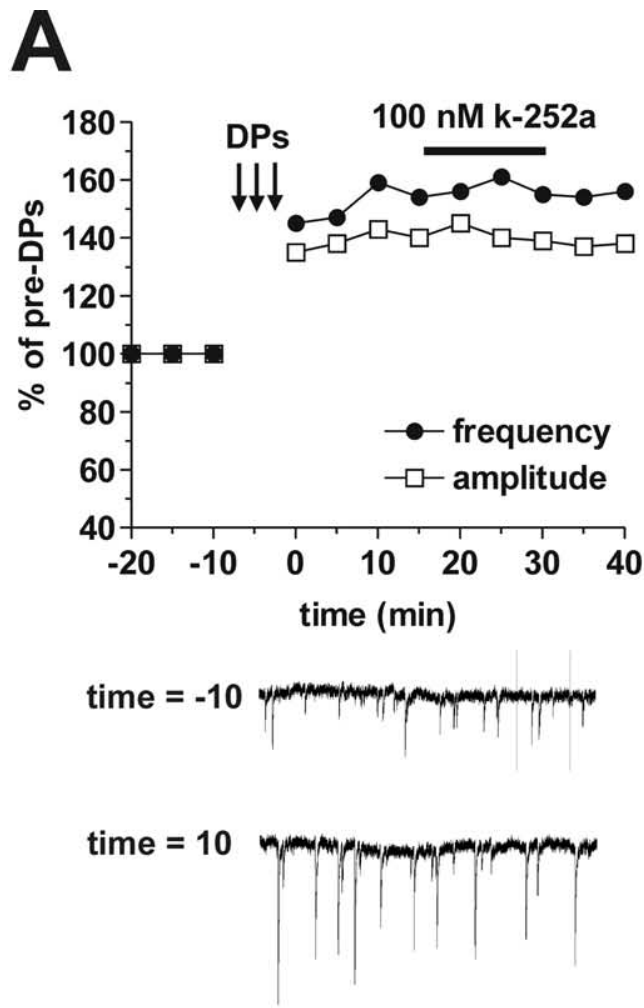

time $=\mathbf{4 0}$

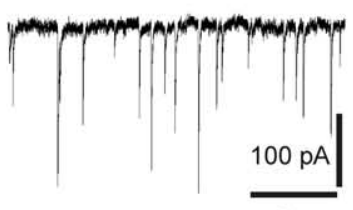

$2 \mathrm{~s}$
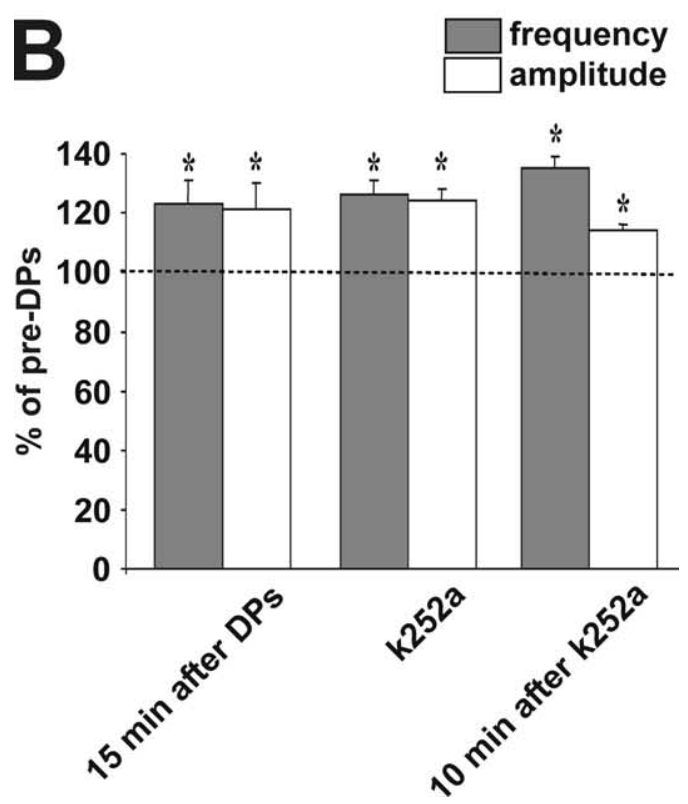

Figure 7. TrkB receptor-coupled PTK activity is not required to maintain $L_{T P} P_{G A B A-A}$. $A$, The graph shows the time course of a single experiment in which $\mathrm{LTP}_{\mathrm{GABA}-\mathrm{A}}$, induced by DPs, is not further affected by the subsequent application of $\mathrm{k}-252 \mathrm{a}$ ( $p>0.05 ; \mathrm{K}-\mathrm{S}$ test). The traces show the $s G_{A B A_{A}}$-PSCs 10 min before DPs (top), 10 min after DPs (middle), and 40 min after DPs (bottom) in the presence of k-252a. $\boldsymbol{B}$, The histogram shows the overall changes of frequency and amplitude of $s \mathrm{AABA}_{A}$-PSCs $15 \mathrm{~min}$ after the DPs, during the application of k-252a, and 10 min after k-252a washout ( $n=8 ;{ }^{*} p<0.05$ compared with pre-DPs; Student's $t$ test).
DPs applied at a frequency of $0.1 \mathrm{~Hz}$. These DPs provoked the activation of voltage-dependent $\mathrm{Ca}^{2+}$ and $\mathrm{Na}^{+}$channels (Caillard et al., 1999; Gubellini et al., 2001). In a recent study, it has been shown that burst stimulations are more effective than tonic stimulation to induce a $\mathrm{Ca}^{2+}$ - and $\mathrm{Na}^{+}$-dependent release of BDNF (Balkowiec and Katz, 2002). Thus, our pattern of stimulation is likely to induce the release of BDNF, which will in turn trigger a cascade of events leading to the induction of GABAergic LTP in the neonatal rat hippocampus. However, BDNF alone does not induce an LTP, but rather a short-term potentiation. This suggests that the induction of a durable LTP might also require, besides BDNF, the electrical activation of the postsynaptic cell. Alternatively, the reversible effect of BDNF might depend on its concentration, and/or the duration of its application, and/or the necessity of other neurotrophins acting in concert with BDNF.

The location of these TrkB receptors and signaling pathway required for the induction of $\mathrm{LTP}_{\mathrm{GABA}-\mathrm{A}}$ is, at present, still to be determined. We have shown previously that $\mathrm{LTP}_{\mathrm{GABA}-\mathrm{A}}$ in the developing rat hippocampus is expressed presynaptically (Caillard et al., 1999; Gubellini et al., 2001), whereas its induction requires a postsynaptic rise in intracellular $\mathrm{Ca}^{2+}$ concentration (McLean et al., 1996; Caillard et al., 1999). This suggests that the information needed to induce $\mathrm{LTP}_{\mathrm{GABA}-\mathrm{A}}$ is transmitted backwards from the postsynaptic pyramidal cell to the presynaptic interneurons. At presynaptic level, the increase in frequency and amplitude $\mathrm{GABA}_{\mathrm{A}}$-PSCs can result from an increase in the firing of presynaptic interneurons or in the probability of GABA release. We have shown previously that the bursting protocol used in the present study also increases the frequency, but not the amplitude, of $\mathrm{mGABA}_{\mathrm{A}}$-PSCs and the amplitude of evoked $\mathrm{GABA}_{\mathrm{A}}$-PSCs (Caillard et al., 1999). These observations suggest that the retrograde messenger required for the expression of $\mathrm{LTP}_{\mathrm{GABA}-\mathrm{A}}$ acts presynaptically to modulate the probability of GABA release. Neurotrophins are good candidates for such a retrograde signaling: released by the postsynaptic element via a $\mathrm{Ca}^{2+}$-dependent mechanism (Lessmann et al., 2003), they can act presynaptically to modulate the probability of GABA release (Poo, 2001; our data). However, additional studies are required to fully address this hypothesis.

\section{Conclusions}

In this study, we provide evidence that PTKs coupled to TrkB receptor family, as well as endogenous TrkB ligands, are required for the induction of GABAergic LTP in the developing rat hippocampus. This form of synaptic plasticity, which is restricted to the first postnatal week of life, is induced by a protocol mimicking the neonatal brain activity leading to the functional maturation of GABAergic synapses (Gubellini et al., 2001). Following the hypothesis that GABAergic LTP represents a mechanism by which synapses are strengthened and selected in the developing brain (Gaiiarsa et al., 2002), here we demonstrate that TrkB ligands play a major role in this process. Thus, the present study further supports a link between GABAergic LTP and the establishment of functional GABAergic synapses in the developing hippocampus, a process involving TrkB signaling.

\section{References}

Aguado F, Carmona MA, Pozas E, Aguilo A, Martinez-Guijarro FJ, Alcantara S, Borrell V, Yuste R, Ibanez CF, Soriano E (2003) BDNF regulates spontaneous correlated activity at early developmental stages by increasing synaptogenesis and expression of $\mathrm{K}^{+} / \mathrm{Cl}^{-}$co-transport. Development 130:1267-1280

Balkowiec A, Katz DM (2002) Cellular mechanisms regulating activity- 
dependent release of native brain-derived neurotrophic factor from hippocampal neurons. J Neurosci 22:10399-10407.

Caillard O, Ben-Ari Y, Gaïarsa J-L (1999) Long-term potentiation of GABAergic synaptic transmission in neonatal rat hippocampus. J Physiol (Lond) 518:109-119.

Castel H, Louiset E, Anouar Y, Le Foll F, Cazin L, Vaudry H (2000) Regulation of $\mathrm{GABA}_{\mathrm{A}}$ receptor by protein tyrosine kinases in frog pituitary melanotrophs. J Neuroendocrinol 12:41-52.

Constantine-Paton M, Cline HT (1998) LTP and activity dependent synaptogenesis: the more alike they are, the more different they become. Curr Opin Neurobiol 8:139-148.

Crair MC, Malenka RC (1995) A critical period for long-term potentiation at thalamocortical synapses. Nature 375:325-328.

Feldman DE, Nicoll RA, Malenka RC, Isaac JT (1998) Long-term depression at thalamocortical synapses in developing rat somatosensory cortex. Neuron 21:347-357.

Gaïarsa JL, Caillard O, Ben Ari Y (2002) Long-term plasticity at GABAergic and glycinergic synapses: mechanisms and functional significance. Trends Neurosci 25:564-570.

Grant SG, O’Dell TJ, Karl KA, Stein PL, Soriano P, Kandel ER (1992) Impaired long-term potentiation, spatial learning, and hippocampal development in fyn mutant mice. Science 258:1903-1910.

Gubellini P, Ben-Ari Y, Gaïarsa J-L (2001) Activity- and age-dependent GABAergic synaptic plasticity in the developing rat hippocampus. Eur J Neurosci 14:1937-1946.

Huang CC, Hsu KS (1999) Protein tyrosine kinase is required for the induction of long-term potentiation in the rat hippocampus. J Physiol (Lond) 520:783-796.

Isaac JTR, Crair MC, Nicoll RA, Malenka RC (1997) Silent synapses during development of thalamocortical inputs. Neuron 18:269-280.

Kano M, Konnerth A (1992) Potentiation of GABA-mediated currents by cAMP-dependent protein kinase. NeuroReport 3:563-566.

Kano M, Fukunaga K, Konnerth A (1996) $\mathrm{Ca}^{2+}$-induced rebound potentiation of gamma-aminobutyric acid-mediated currents requires activation of $\mathrm{Ca}^{2+} /$ calmodulin-dependent kinase II. Proc Natl Acad Sci USA 93:13351-13356.

Kirkwood A, Lee HK, Bear MF (1995) Co-regulation of long-term potentiation and experience-dependent synaptic plasticity in visual cortex by age and experience. Nature 375:328-331.

Knusel B, Hefti F (1992) K-252 compounds: modulators of neurotrophin signal transduction. J Neurochem 59:1987-1996.

Komatsu Y (1994) Age-dependent long-term potentiation of inhibitory synaptic transmission in rat visual cortex. J Neurosci 14:6488-6499.
Kotak VC, Sanes DH (2000) Long-lasting inhibitory synaptic depression is age- and calcium-dependent. J Neurosci 20:5820-5826.

Kotak VC, Dimattina C, Sanes DH (2001) GABA $_{B}$ and Trk receptor signaling mediates long-lasting inhibitory synaptic depression. J Neurophysiol 86:536-540.

Lessmann V, Gottmann K, Malcangio M (2003) Neurotrophin secretion: current facts and future prospects. Prog Neurobiol 69:341-374.

Marty S, Berninger B, Carroll P, Thoenen H (1996) GABAergic stimulation regulates the phenotype of hippocampal interneurons through the regulation of brain-derived neurotrophic factor. Neuron 16:565-570.

Marty S, Wehrlé R, Sotelo C (2000) Neuronal activity and brain-derived neurotrophic factor regulate the density of inhibitory synapses in organotypic slice cultures of postnatal hippocampus. J Neurosci 20:8087-8095.

McLean HA, Caillard O, Ben-Ari Y, Gaïarsa J-L (1996) Bidirectional plasticity expressed by GABAergic synapses in the neonatal rat hippocampus. J Physiol (Lond) 496:471-477.

O'Dell TJ, Kandel ER, Grant SG (1991) Long-term potentiation in the hippocampus is blocked by tyrosine kinase inhibitors. Nature 353:558-560

Poo MM (2001) Neurotrophins as synaptic modulators. Nat Rev Neurosci 2:24-32.

Ross AH, McKinnon CA, Daou MC, Ratliff K, Wolf DE (1995) Differential biological effects of K252 kinase inhibitors are related to membrane solubility but not to permeability. J Neurochem 65:2748-2756.

Schwyzer L, Mateos JM, Abegg M, Rietschin L, Heeb L, Thompson SM, Luthi A, Gahwiler BH, McKinney RA (2002) Physiological and morphological plasticity induced by chronic treatment with NT-3 or NT-4/5 in hippocampal slice cultures. Eur J Neurosci 16:1939-1948.

Seil FJ, Drake-Baumann R (2000) TrkB receptor ligands promote activitydependent inhibitory synaptogenesis. J Neurosci 20:5367-5373.

Shatz CJ (1990) Impulse activity and the patterning of connections during CNS development. Neuron 5:745-756.

Shelton DL, Sutherland J, Gripp J, Camerato T, Armanini MP, Phillips HS, Carroll K, Spencer SD, Levinson AD (1995) Human Trks: molecular cloning, tissue distribution, and expression of extracellular domain immunoadhesins. J Neurosci 15:477-491.

Tanaka T, Saito H, Matsuki N (1997) Inhibition of GABA ${ }_{A}$ synaptic responses by brain-derived neurotrophic factor (BDNF) in rat hippocampus. J Neurosci 17:2959-2966.

Vicario-Abejon C, Collin C, McKay RD, Segal M (1998) Neurotrophins induce formation of functional excitatory and inhibitory synapses between cultured hippocampal neurons. J Neurosci 18:7256-7271. 